\title{
Daniel Carrión García: estudio iconográfico y antropológico forense
}

\section{Daniel Carrion-Garcia: iconographic and forensic anthropological study}

\section{Correspondencia}

Ricardo Iván Álvarez Carrasco ralvarezcarrasco@yahoo.com

Recibido: 25/10/2016

Aprobado: 16/11/2016

Citar como: Álvarez Carrasco Rl. Daniel Carrión García: estudio iconográfico y antropológico forense. Acta Med Peru. 2016;33(4):322-9

\author{
Ricardo Iván Álvarez Carrasco ${ }^{1,2}$ \\ 1 Asociación de Historia de la Medicina Peruana. Lima, Perú. \\ 2 Instituto Nacional Materno Perinatal. Lima, Perú.
}

\section{RESUMEN}

Este artículo tiene como propósito brindar aportes objetivos sobre la iconografía de Daniel Carrión García (1857-1885), héroe y mártir de la medicina peruana que se basan en una investigación de las tres fotografías que se le atribuyen, la cual comprende tres aspectos: el histórico, en el que se hace una recopilación de las principales fuentes bibliográficas; el técnico fotográfico, en el que revisamos el estado tecnológico de este arte en la época en la que se captaron dichas fotografías; y el antropológico forense, que nos permite utilizar los métodos más avanzados de identificación facial. Basados en estos elementos objetivos hemos concluido que la llamada "Fotografía familiar" es el estándar de oro que debe emplearse como elemento de comparación frente a la "Fotografía individual" y la "Fotografía militar", determinando que existen elementos suficientes para afirmar que la primera es una imagen genuina de Carrión, mientras que sólo existen indicios razonables con respecto a la segunda, debiendo profundizarse las investigaciones respecto a ella.

Palabras clave: Perú, Historia de la medicina; Carrión, Daniel A.; Fotografía (fuente: DeCS BIREME).

\begin{abstract}
This paper aims to provide objective contributions on the iconography of Daniel Carrion-Garcia (1857-1885), hero and martyr of Peruvian medicine, based on a detailed investigation of the three photographs attributed to him, comprising three aspects: History, in which a compilation of the main bibliographical sources is made; the photographic technique, in which we reviewed the current state of the art of photography at the time when these images were captured; and forensic anthropology, which allowed us to use the most advanced methods for facial identification. Based on these objective elements we have concluded that the so-called "family photograph" is the gold standard, which should be used as an element of comparison against the "individual photography" and the "military photography", determining that there are sufficient elements to affirm that the first image is a genuine portrait image of Daniel Carrion, while there are only reasonable clues with respect to the second, and further investigations must be performed regarding this image.
\end{abstract}

Keywords: Peru, History of medicine; Carrion, Daniel A.; Photography (source: MeSH NLM). 


\section{INTRODUCCIÓN}

En la bibliografía nacional se ha evidenciado una interesante dicotomía en la que contrasta la prolijidad con la que se ha investigado la Enfermedad de Carrión frente a la superficialidad con la que se ha abordado la biografía de Daniel Carrión García. Salvo contadas excepciones, se desarrolló como un trabajo de gabinete sin las indispensables pesquisas de campo; los autores repitieron los lugares comunes y las inexactitudes publicadas por sus antecesores, y hubo muy pocos aportes provenientes de fuentes primarias lo que ocasionó numerosas correcciones a través del tiempo, las mayores entre las biografías de los peruanos ilustres.

El colmo de la falta de acuciosidad respecto a la memoria de Carrión se encontró patente, durante cuarentaicinco años, en su cripta mausoleo situada en el patio principal del Hospital Nacional Dos de Mayo, en donde la gran losa negra que se yergue detrás del catafalco de nuestro personaje decía textualmente: "Nació el 12 de agosto de 1857". Este error pasó inadvertido para la inmensa mayoría de los miembros de la orden médica, en esa circunstancia tuvimos el honor de señalarlo en nuestro libro Daniel Carrión García. Estudio histórico, iconográfico y antropológico forense (2015); gracias a ello las actuales autoridades del Consejo Nacional del Colegio Médico del Perú lograron rectificar esta ignominia, y desde este año se luce la genuina fecha de su nacimiento, el 13 de agosto de 1857.

Esta desprolijidad también fue el origen de la polémica sobre el verdadero rostro de Daniel Carrión García, cuya iconografía es igualmente una de las más controvertidas entre nuestros héroes y personajes notables. Esta polémica tuvo su punto de partida en la publicación de un grabado en la portada de la revista $L a$ Crónica Médica, el 31 de octubre de 1885, en el que claramente se modificó su aspecto real, y que fue la primera imagen que se divulgó al gran público.

Si a ello agregamos la carencia de estudios sobre dicho asunto con un adecuado basamento histórico y tecnológico, entonces comprenderemos la razón por la que dicha polémica ha subsistido hasta nuestros días.

\section{Antecedentes de la fotografía en el Perú}

El 19 de agosto de 1839, el francés Louis Daguerré presentó ante las Academias de Ciencias y Bellas Artes de París un invento que permitía obtener imágenes sin necesidad del dibujo o la pintura ${ }^{[1]}$. Las imágenes obtenidas mediante esta técnica se denominaron genéricamente daguerrotipo y tenían el inconveniente que solo se podía obtener un original sobre una plancha de metal, sin la posibilidad de lograr copia alguna.

En Inglaterra, William Henry Fox Talbot había trabajado paralelamente en un sistema para capturar las imágenes que permitía obtener un original en papel y copias ilimitadas del mismo, el cual llamó calotipo. Cuando tuvo las primeras noticias del anuncio de Daguerré, se apresuró en dar a conocer los resultados de sus trabajos.
El 25 de septiembre de 1839, poco más de un mes del anuncio efectuado en Francia, el diario El Comercio de Lima insertó una nota que daba cuenta de este invento; sin embargo, debieron trascurrir casi tres años para que llegara el primer daguerrotipista al Perú, el francés Maximiliano Danti, quien arribó procedente de Valparaíso el 8 de mayo de 1842, e instaló su negocio en el número 255 de la calle Mantas de Lima donde sólo trabajó hasta fines de aquel año ${ }^{[2]}$.

Así se inició la era del daguerrotipo en nuestro país, la cual se extendió hasta la década de 1860, sin embargo, los altos costos, el largo tiempo de exposición y la imposibilidad de producir copias del original impidieron que se difundiera de manera suficiente; por ello, los primeros estudios no tuvieron una vida estable, un número indeterminado de daguerrotipistas trabajaron por lapsos breves y el nombre de muchos de ellos se ha perdido irremediablemente.

\section{El arte fotográfico en Lima, durante la época de Daniel Carrión García}

En 1853, Jacinto Pedevilla, el primer daguerrotipista peruano, fue el introductor de la técnica del colodión húmedo, que permitía obtener un negativo que podía positivarse ilimitadas veces, hecho que significó el inicio del fin del daguerrotipo en nuestro país ${ }^{[3]}$. El advenimiento de esta nueva técnica inauguró una época de costos sensiblemente menores, permitiendo que la fotografía fuera más accesible para la sociedad limeña ${ }^{[3]}$.

Entre 1879 y 1885 , la época en la que se habrían tomado los retratos atribuidos a Carrión, la técnica fotográfica dominante era el colodión húmedo tanto en Lima como en el resto de la República ${ }^{[4]}$. Dicha técnica coexistió con otras dos: el ambrotipo y el ferrotipo, mientras que el calotipo no se introdujo en nuestro país ${ }^{[3]}$

Las características físicas de los ejemplares positivos y negativos obtenidos mediante la técnica del colodión húmedo eran las siguientes:

\section{- Positivos}

Eran imágenes impresas sobre un papel fotográfico muy delgado, a tal punto que para conservarlas adecuadamente era indispensable pegarlas sobre un soporte de cartón que los franceses denominaron passepartout, y que en esta parte del mundo fueron llamados marialuisa o paspartú ${ }^{[4]}$. Los estudios fotográficos más importantes hacían imprimir su logotipo en este cartón y que usualmente estaba acompañado por la dirección del negocio y, en algunos casos, la mención de los premios que habían obtenido por su participación en los diversos eventos nacionales e internacionales ${ }^{[4]}$.

En Lima gran parte de los fotógrafos que emplearon el colodión húmedo, obtenían las copias positivas utilizando el papel albuminado como parte del procedimiento del revelado; por desgracia este material solía deteriorarse con el pasar de los años, lo que se evidenciaba por el desvanecimiento y 


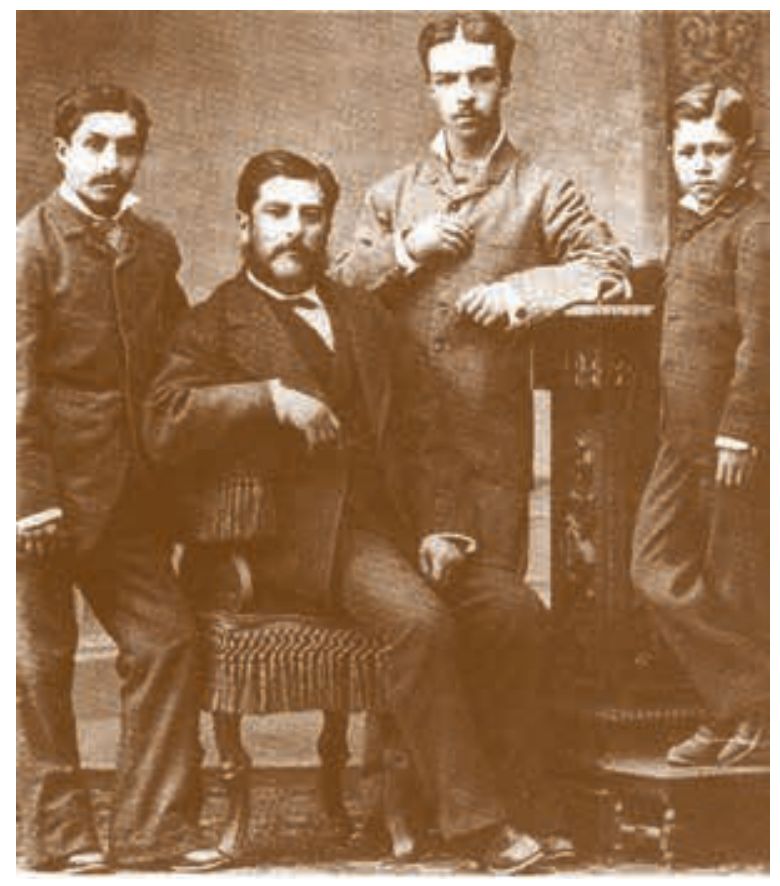

Figura 1. Fotografía familiar. De izquierda a derecha: Daniel Carrión García, Alejandro Valdivieso Riofrío, Teodoro Crisanto Valdivieso García y Manuel Valdivieso García.

amarillentamiento de la imagen ${ }^{[3]}$. Aquel método fue usado por Courret, Pease, Maunoury, Richarson y Garreaud [4].

Otra forma de obtener copias positivas era aplicar el procedimiento de revelado al carbón, donde el color definitivo dependía del pigmento utilizado, aunque por lo general se procuraba que el acabado fuera lo más parecido posible al de una copia albuminada ${ }^{[3]}$. Con tal procedimiento se obtenían imágenes que prácticamente no se modificaban con el trascurrir del tiempo, por lo que se las publicitaba como "fotos inalterables"; no obstante, debido a lo laborioso del proceso, muy pocos fotógrafos lo adoptaron y en Lima sólo dos ofrecían estas imágenes: Rafael Castillo y Alberto Rodríguez ${ }^{[3,4]}$.

\section{- Negativos}

Eran placas rectangulares de vidrio con superficies perfectamente lisas y limpias con el fin de obtener imágenes nítidas y sin manchas, para ello debían permanecer húmedas durante el procedimiento de toma y revelado de la imagen ${ }^{[4]}$. Posteriormente mantenían la imagen negativa en suspensión, permitiendo reproducirla numerosas veces ${ }^{[4]}$.

\section{Los retratos de Daniel Carrión García}

Los retratos que se atribuyen a Carrión, con absoluta certeza, se tomaron utilizando la técnica del colodión húmedo; por ello los ejemplares originales, positivos o negativos, deben concordar con las características físicas que hemos descrito, en caso contrario se debe sospechar que estamos frente a falsificaciones o copias efectuadas en un período posterior. Hasta la fecha se han dado a conocer tres retratos de Daniel Carrión García ${ }^{[4]}$ :

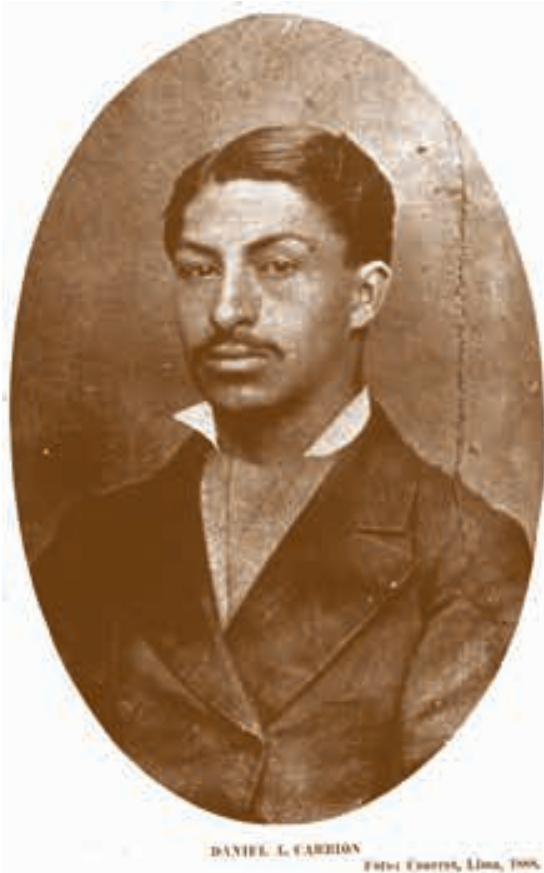

Figura 2. Fotografía Individual. Daniel Carrión García.

1. La Fotografía Familiar, en la que aparece en compañía de su padrastro Alejandro Valdivieso Riofrío y sus medios hermanos Teodoro Crisanto y Manuel Mario Valdivieso García (Figura 1).

2. La Fotografía individual, en la que aparece vestido de civil y obviamente solo (Figura 2).

3. La Fotografía militar, que es de reciente aparición y en la que nuestro personaje se hallaría vestido con un uniforme militar en la época de la Guerra del Pacífico (Figura 3).

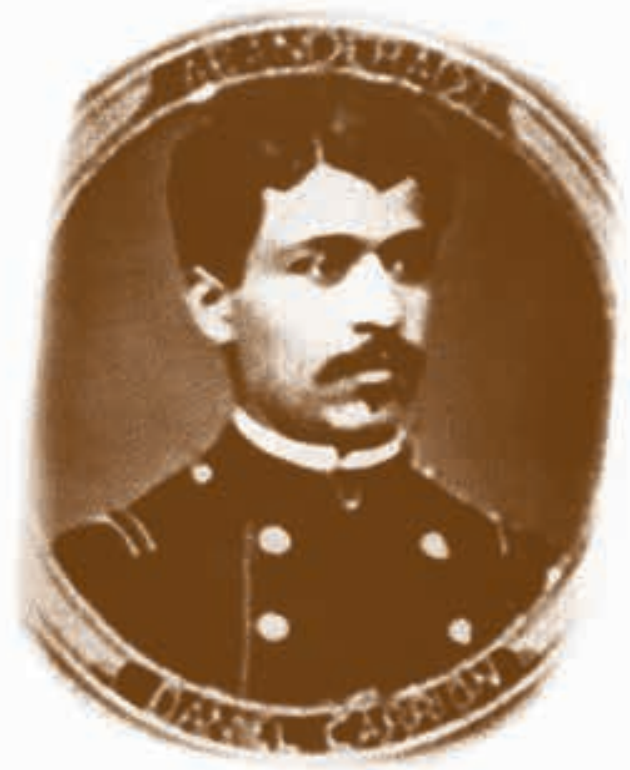

Figura 3. Fotografía militar. 
A continuación, analizaremos cada una de ellas desde la perspectiva histórica, icnográfica y antropológica forense.

\section{La Fotografía familiar}

Contiene a cuatro personas, que dispuestas, desde la perspectiva del lector, son las siguientes: de pie y al extremo izquierdo se halla Daniel Carrión García, al centro y sentado aparece su padrastro Alejandro Valdivieso Riofrío, y al lado derecho encontramos a sus medios hermanos Teodoro Crisanto y Manuel Mario Valdivieso García, ambos de pie (Figura 1). No ha sido posible hallar un ejemplar original de esta imagen, ya que los archivos fotográficos de los principales estudios limeños activos entre 1879 y 1885 no se han conservado sistemáticamente por ninguna entidad pública o privada ${ }^{\left[{ }^{[}\right]}$.

En el año 2011, cuando iniciamos nuestra investigación, los dos principales archivos fotográficos abiertos al público eran los de la Biblioteca Nacional del Perú (BNP) y del Instituto Fotográfico Eugenio Courret (IFEC), por lo que se recurrió a ellos para llevar a cabo esta etapa de las pesquisas ${ }^{[5]}$.

En la Sala de Afiches y Fotografía de la BNP, en su sede de San Borja (Lima), sólo se halló un retrato de Daniel Carrión García, que está identificado con la ficha que a la letra dice [5]: "F610 C2. CARRIÓN, DANIEL A., 1859-1885. Daniel A. Carrión, notable médico peruano, descubridor del virus de la Verruga. $24 \times 18 \mathrm{~cm}$. Fotografía del año 1880".

Es muy probable que esta ficha se haya elaborado antes de 1949, año en que recién quedó dilucidada la fecha del nacimiento de nuestro personaje. Otra posibilidad es que el encargado de hacerlo no tuviera la precaución de consignar datos veraces, pues desde la segunda década del siglo XX se sabía que la Enfermedad de Carrión no tenía como agente causal a un "virus", y hasta hoy no existen datos concluyentes sobre la fecha en que se captó dicha imagen, por lo que afirmar que se hizo en 1880, resulta aventurado.

Un ligero examen de este retrato nos permitió comprobar que se trataba de una imagen cercenada de la Fotografía familiar (Figura 4), y que además era una simple copia, lo que corroboramos por el material sobre la que estaba impresa (papel fotográfico grueso y mate) y al observar en su reverso el sello del fotógrafo limeño Luís Severo Ugarte Ronceros [5]. En 1885, año en que falleció Carrión, Ugarte sólo tenía ocho años, recién en 1892 inició sus actividades en el ramo como dibujante del estudio Courret y luego, en 1895, en el de Fernando Garreaud ${ }^{[6]}$, por ello es imposible que pudiera captar aquella imagen.

En el 2015, comprobamos que esta situación seguía igual, es decir, que la BNP no poseía o no tenía disponible ninguna imagen original positiva y/o negativa de Daniel Carrión ${ }^{[4]}$. En dicho archivo existen miles de ejemplares de diversos fotógrafos que actuaron en el Perú, desde mediados del siglo XIX, que no han sido fichados y por lo tanto no están a la disposición de los investigadores ${ }^{[4]}$.

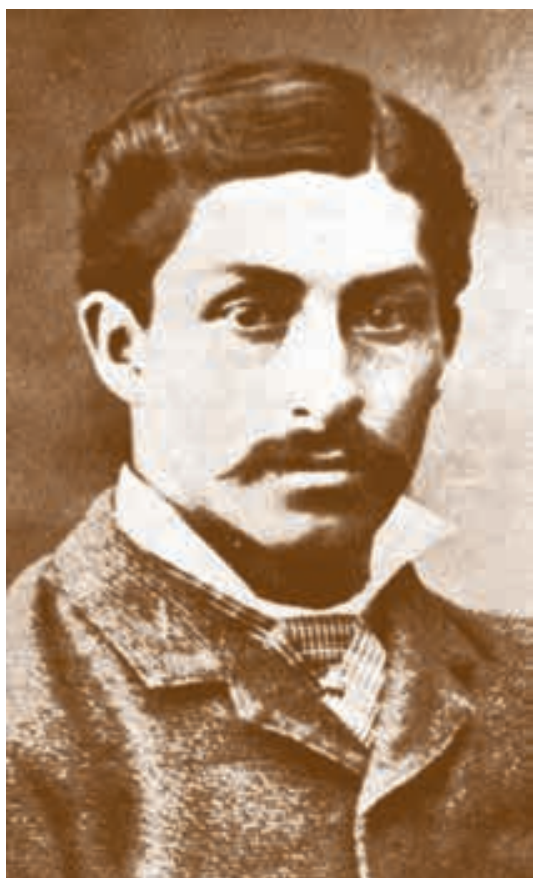

Figura 4. Daniel Carrión García. Parte cercenada de la fotografía familiar.

En cuanto al archivo del IFEC, nos remitimos a la versión del doctor Bertilo Malpartida Tello, distinguido cirujano de tórax y cardiovascular quien, en septiembre de 2011, solicitó a dicho establecimiento el retrato de nuestro héroe y mártir ${ }^{[7]}$. Como consecuencia de ello se le entregó una imagen que prácticamente era la misma que poseía la BNP, por lo que de manera análoga concluimos que el IFEC tampoco poseía imágenes originales positivas y/o negativas de Daniel Carrión, ya que si las tuviera, hubiera proporcionado el retrato íntegro, tal como se captó en el estudio fotográfico ${ }^{[4]}$.

Es oportuno esclarecer enfáticamente que el IFEC nunca tuvo ninguna relación con el estudio fotográfico de Eugene Courret, excepto la de compartir el nombre del artista francés; incluso Andrés Herrera Cornejo, dueño del IFEC, no había nacido cuando quebró el referido estudio. A través de los años fue adquiriendo imágenes, originales y copias, captadas por diversos fotógrafos que trabajaron en el Perú desde el sigloXIX, por lo que no todas las fotografías existentes en aquel archivo provenían del estudio fotográfico de Eugene Courret ${ }^{[4]}$.

En el 2012, el archivo del IFEC fue adquirido por el Instituto de Educación Superior Tecnológico Privado Centro de la Imagen (IESTPCI), ubicado en el número 815 de la avenida 28 de julio, en el distrito limeño de Miraflores, a pocos metros del Centro de Convenciones Daniel Alcides Carrión del Colegio Médico del Perú ${ }^{[4]}$.

En diciembre del 2014, Cecilia Salgado, encargada de la conservación del archivo del IESTPCI, nos refirió que el material adquirido al IFEC constaba de 32622 piezas, casi todas ellas 


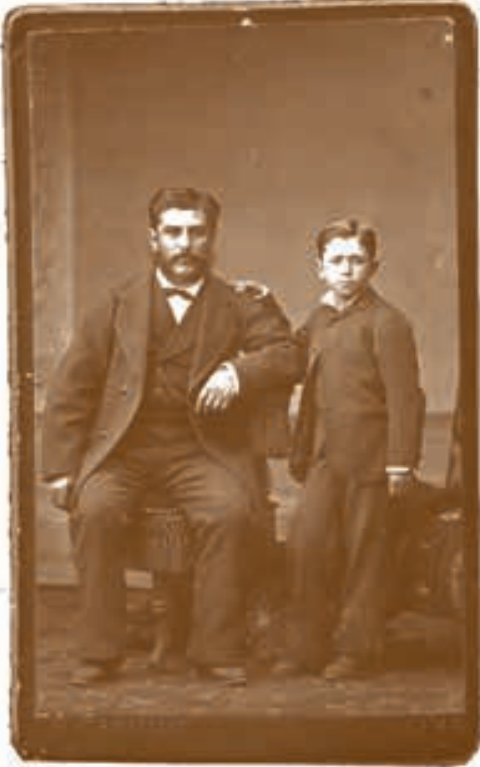

Figura 5. Alejandro Valdivieso Riofrío acompañado de Manuel Valdivieso García.

negativos originales, y de este total sólo 30893 imágenes se atribuyeron inicialmente al estudio fotográfico de Eugenio Courret ${ }^{[4]}$, aunque luego se estableció que su verdadero autor había sido el artista Elías Del Águila. Al examinar estos negativos, sólo uno databa de 1884, mientras que el resto eran posteriores a 1887, por tanto, en dicho archivo no existe ninguna placa de Daniel Carrión García, ya que nuestro personaje falleció en $1885^{[4]}$.

Sólo quedaba investigar si Herrera Cornejo conservó alguna fotografía original de Carrión, para ello contactamos con su hijo José Antonio Herrera de Rivero, fotógrafo profesional y docente en diversas instituciones, quien el 11 de febrero de 2015 nos respondió brevemente a través del correo electrónico: "Lo sentimos mucho pero no hemos podido ubicar ninguna imagen original, salvo copias" [4]. Con ello corroboramos que el archivo de Herrera Cornejo no poseyó una fotografía original, positiva y/o negativa, de Daniel Carrión García.

En el Archivo Daniel Carrión de la Facultad de Medicina de San Fernando tampoco se halló un ejemplar original de la Fotografía familiar $^{[4]}$.

Hace algunos años hicimos un hallazgo importante, se trataba del positivo original de un retrato de Alejandro Valdivieso Riofrío y su hijo Manuel Mario Valdivieso García (Figura 5), el cual tenía el sello del estudio fotográfico de Rafael Castillo, y que nos llamó poderosamente la atención, ya que ambas personas tenían el mismo aspecto físico y la vestimenta que en la Fotografía familiar, aunque con posturas corporales diferentes ${ }^{[4]}$.

Estas notorias diferencias posturales impiden que aquel retrato sea el producto de la manipulación fotográfica, en la que eliminando a las demás personas que aparecen en la Fotografía familiar, se consiga juntar artificialmente al padre con el menor de sus hijos. De ello concluimos que el retrato identificado como la Figura 5, se tomó en la misma sesión en la que se captó la Fotografía familiar (Figura 1), y por tanto, ambas corresponden al estudio de Rafael Castillo ${ }^{[4]}$.

En favor de esta tesis, luego encontramos dos retratos originales, el primero de María Dolores García Navarro, madre de nuestro héroe y mártir, quien aparece sentada en ligero perfil izquierdo, y que también fue captada en el estudio de Rafael Castillo (Figura 6) ${ }^{[4,5]}$. En su reverso hay una inscripción ininteligible que parece incluir la fecha "19 de abril de 1886", y que coincidiría con la época en que su marido, Alejandro Valdivieso, vino a Lima para intentar recuperar su quebrantada salud, pero falleció el 4 de julio de ese año ${ }^{[4,5]}$. Esta imagen se ha publicado en diversas ocasiones, pero ningún autor presentó su versión original, razón por la cual no se pudo identificar al fotógrafo que la captó ${ }^{[4,5]}$.

El segundo retrato corresponde a Teodoro Crisanto Valdivieso García (Figura 7), hermano de Daniel, quien posó de pie, en medio perfil derecho, vestido con chaqué y portando una llamativa leontina rematada por lo que parece ser un pequeño reloj, que presumimos es de un metal precioso, la cual igualmente se tomó en el estudio de Rafael Castillo, como consta por el sello impreso en dicho ejemplar ${ }^{[4]}$. En el reverso se lee la inscripción de puño y letra: "En prueva (sic) de cariño a mi distinguido amigo Julio N. Bao. Teodoro Valdivieso", aunque no se consignó ninguna fecha, creemos que fue muy cercana a su muerte, el 19 de diciembre de $1886^{[4]}$.

Las Figuras 5, 6 y 7 tienen las características físicas de los ejemplares positivos obtenidos mediante el método del colodión húmedo, y revelados por el procedimiento al carbón, que era casi exclusivo de Rafael Castillo, con la sola excepción de Alberto Rodríguez ${ }^{[3]}$. Con todos estos elementos de juicio 


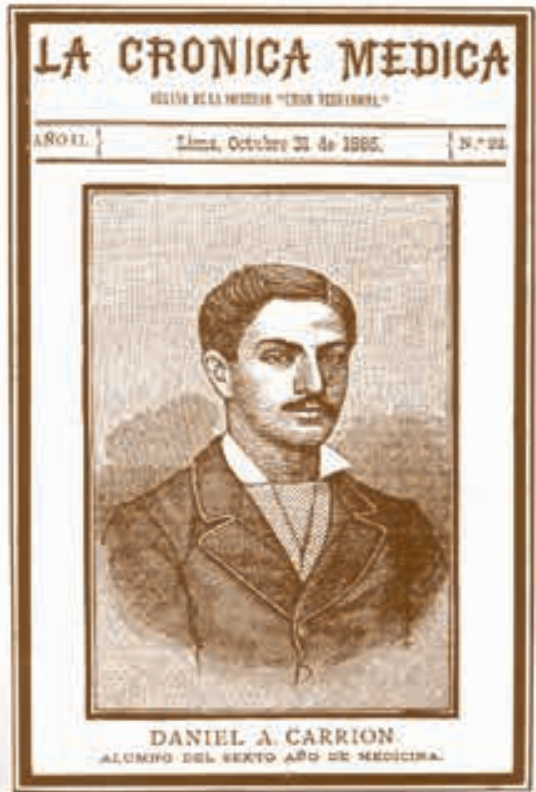

Figura 8. Grabado de Daniel Carrión García aparecido en La Crónica Médica.

llegamos a la convicción que la familia Valdivieso-García tuvo la costumbre, por lo menos en aquellos años, de recurrir a Rafael Castillo cada vez que deseaban retratarse en nuestra ciudad capital ${ }^{[4]}$.

Rafael Castillo Gómez nació en la ciudad de Piura, el año de 1844; desde 1864 figuró como operario en el estudio fotográfico de Vilroy L. Richardson en Lima, el cual dirigió a partir de enero de 1867, por ausencia del dueño ${ }^{[4]}$. Luego se independizó fundando la llamada Fotografía Nacional, donde se convirtió en el único rival serio de Eugenio Courret; en 1880 se incorporó al Ejército de Reserva para la defensa de Lima contra el invasor chileno, no habiendo evidencia de que su estudio continuara activo durante el cautiverio de nuestra capital; falleció en Lima, el 20 de setiembre de $1887^{[4]}$.

Concluimos que la Fotografía familiar es un retrato auténtico de Daniel Carrión García, tomado por el artista Rafael Castillo, y por tal motivo debe ser utilizado como el estándar de oro frente a los otros dos retratos atribuidos a nuestro héroe y mártir ${ }^{[4]}$. En cuanto a la fecha en que se captó, no hallamos ningún elemento objetivo que nos permita señalarla categóricamente, sin embargo, en vista que Manuel Mario Valdivieso García aparenta entre seis y ocho años de edad, la fecha probable oscilaría entre 1883 y $1885^{[4]}$.

\section{La Fotografía individual}

La Fotografía individual de Carrión es una imagen en la que nuestro personaje aparece solo, usualmente ha sido publicada de medio perfil izquierdo, vistiendo un chaqué clásico de la época (Figura 2). Aunque parezca un detalle poco relevante, hay que diferenciarla de la imagen cercenada de la Fotografía familiar, en la que también aparece solo (Figura 4).

Esta se tomó como modelo para el grabado que apareció en $L a$ Crónica Médica (31 de octubre de 1885) ${ }^{[8]}$, en el que Carrión se

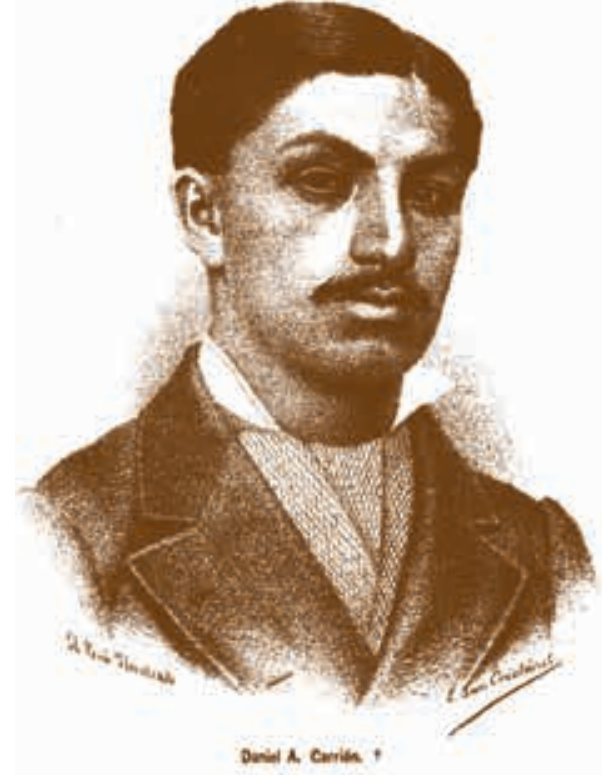

Figura 9. Dibujo de Daniel Carrión García aparecido en la revista El Perú llustrado realizado por Evaristo San Cristóval León.

halla en medio perfil derecho (Figura 8). Aquel grabado se obtuvo por la transposición óptica de dicha fotografía, que se labró sobre una plancha de metal con la que se le estampó en la portada de aquella publicación, sin embargo, son notorios los retoques que se efectuaron para hacerlo socialmente aceptable ${ }^{[9]}$.

La Fotografía individual también la utilizó el artista Evaristo San Cristóval León, para realizar el dibujo que se publicó el 12 de noviembre de 1887, en la primera plana del número 27 de la revista El Perú llustrado (Figura 9) ${ }^{[10]}$. Dicho artista la tomó nuevamente como base para el dibujo que se editó en la portada del número 8 de la revista Ilustración Americana, del 15 de octubre de 1890 (Figura 10), lo cual desvirtúa la versión que se trata de un dibujo espurio, extraño a la pluma de San Cristóval ${ }^{[4]}$.

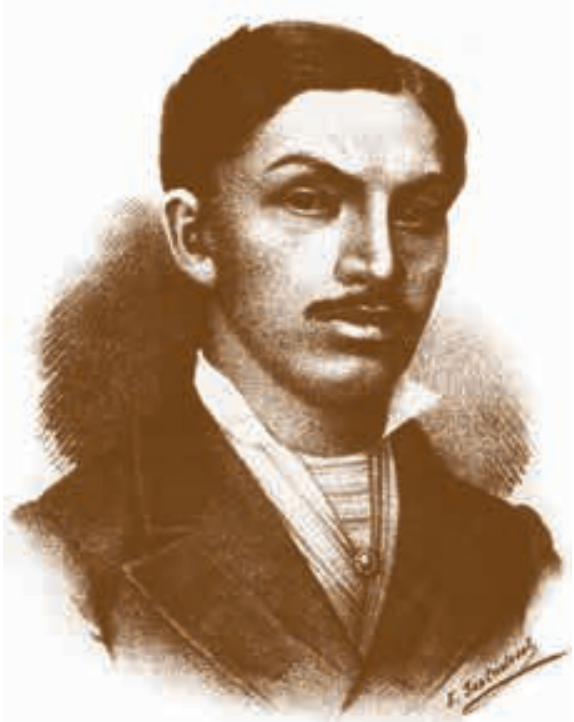

Figura 10. Reproducción del dibujo de Daniel Carrión García aparecido en la revista llustración Americana. 
Una de las primeras veces que se publicó la Fotografía individual, fue en la revista Anales de la Facultad de Medicina (Lima, 1925), que la insertó entre las páginas 54 y 55, para ilustrar el artículo Apuntes para una bibliografía peruana de la enfermedad de Carrión escrito por el doctor Hermilio Valdizán, el padre de la historiografía médica peruana ${ }^{[11]}$. Este retrato se fechó en $1888^{[11]}$, lo cual es erróneo ya que Carrión había fallecido tres años antes.

Siendo dicha imagen de dominio público, por lo menos desde 1925, ninguno de los médicos que aún vivían por entonces, y que conocieron personalmente a Carrión, presentó reclamo alguno sobre la autenticidad de dicha imagen, entre ellos estaban los doctores Ricardo Flores Gaviño, Evaristo Manuel Chávez, Leonidas Avendaño Ureta, Julián Arce Ramírez, Casimiro Medina y Ernesto Mestanza ${ }^{[4]}$.

El 5 de octubre de 1954, se inauguró el Museo Daniel Alcides Carrión de la Facultad de Medicina de San Fernando, que se formó sobre la base de una importante colección de documentos relativos a nuestro héroe y mártir, que fueron donados por el entonces estudiante de medicina José Benigno Peñaloza Jarrín, que a su vez los heredó de su padre, Augusto Peñaloza Vega, diputado por el Departamento de Junín y antiguo pupilo de María Dolores García Navarro, quien los guardó "durante muchos años como un legado de la madre del valeroso estudiante" ${ }^{[12]}$.

Existen varias imágenes captadas el día de la inauguración, y por lo menos en dos de ellas aparece la Fotografía individual (Anales de la Facultad de Medicina. 1954; 37(4):774-814), como parte de las piezas en exhibición, incluso una de ellas se acompaña de la leyenda: "Copias fotostáticas y retratos de Daniel A. Carrión y de la Sra. Dolores García de Valdivieso, madre de Carrión" [22]

¿Es concebible que el doctor Augusto Peñaloza, quien estrechó una entrañable relación afectiva con la madre de nuestro personaje y que se constituyó como el depositario del legado de Daniel Carrión, consintiera la exhibición de un retrato apócrifo? La respuesta obviamente es no ${ }^{[4]}$.

\section{Fotografía militar}

En los últimos tiempos ha surgido una tercera imagen de Carrión, la cual se publicó en la página 125 del libro La Columna Pasco (2013) de César Pérez Arauco, en la que aparece con uniforme militar, formando parte de una composición fotográfica de la oficialidad del batallón 23 de diciembre, en su condición de abanderado (Figura 3) ${ }^{[13]}$. Dicha imagen también fue presentada por Oscar Pamo en su artículo Sobre el rostro de Carrión ${ }^{[14]}$.

En la página 344 del libro La Universidad Mayor de San Marcos y la Guerra del Pacífico de Jenaro Ernesto Herrera Torres, se detalla la relación de la plana mayor de dicho batallón, en la que se señala: "Abanderado - Subteniente temporal, D. Daniel Carreño" [55]. La misma información se publicó en el libro La Gesta de Lima (1981), que contiene la relación detallada de la oficialidad del Ejército de Reserva, y en la plana mayor del Batallón $\mathrm{N}^{\circ} 36$ se dice textualmente: "Abanderado - Subteniente temporal Daniel Carreño" ${ }^{[16]}$.
Durante la Guerra del Pacífico no fue infrecuente que en los extensos listados de los jefes, oficiales y tropa se cometieran errores al registrar sus nombres y apellidos, ello hace posible que el mencionado Daniel Carreño pudiera ser en realidad Daniel Carrión, aunque ello no lo podemos afirmar categóricamente ${ }^{[4]}$.

De la revisión prolija de numerosas fuentes bibliográficas, todo parece indicar que Carrión, muy probablemente, participó en alguna plaza del servicio sanitario durante la batalla de Miraflores, posiblemente en el Hospital Francés o en alguno de los hospitales de sangre instalados para esta ocasión, pero no existe hasta hoy ninguna evidencia definitiva sobre su intervención en la de San Juan ${ }^{[4]}$. Obviamente esta hipótesis puede modificarse si más adelante se halla alguna prueba material que defina la identidad del mencionado Daniel Carreño u otra que precise este asunto, pero por desgracia mucha de la documentación de la Guerra del Pacífico se destruyó o permanece en colecciones privadas inaccesibles para los investigadores ${ }^{[4]}$.

En cuanto a la alegoría fotográfica en la que Carrión figura como abanderado del batallón 23 de diciembre, evidentemente se trata de una composición artística, como otras tantas que aparecieron en los años de la post guerra, elaboradas por impresores particulares sin la necesaria rigurosidad histórica ${ }^{[4]}$.

Independientemente a estas consideraciones, el martes 24 de marzo de 2015, después de varios años de gestión, el Ministerio de Defensa accedió a colocar una placa conmemorativa a la participación de Carrión en la defensa de Lima, en la Cripta de los Héroes de la Guerra del Pacífico, cuya inscripción dice: "Héroe nacional, mártiry maestro de la medicina peruana Daniel Alcides Carrión García, combatienteen la defensa de Lima 13 y 15 enero 1881. Heroico sacrificio por la humanidad 05 octubre 1885. Lima, febrero $2015^{\prime \prime}$ [4].

\section{Estudios antropológico forenses de las fotografías de Daniel Carrión García}

La tecnología médica de nuestro tiempo permite hacer el estudio científico de las fotografías atribuidas a Daniel Carrión García mediante técnicas antropológico forenses, la primera de ellas es la comparación del cráneo del individuo objeto de la investigación con la fotografía que se le adjudica ${ }^{[4]}$. Lamentablemente el paradero de la osamenta de nuestro héroe y mártir aún no se ha podido establecer de manera inequívoca, razón por la cual por ahora no es factible aplicar dicha técnica.

La segunda consiste en utilizar un software especialmente desarrollado, el cual permite confrontar la fotografía del individuo investigado, que esté catalogada como el estándar de oro, frente a otra cuya legitimidad se halle en discusión ${ }^{[4]}$. Existen dos trabajos publicados en los que se aplicó esta técnica para estudiar las fotografías de Carrión:

- En 2014 se editó el artículo Sobre el rostro de Carrión (Revista de la Sociedad Peruana de Medicina Interna. Número 1, volumen 27), cuyos autores fueron Oscar Guillermo Pamo Reyna, Danny Jesús Humpire Molina, y Luís Fucay Guin ${ }^{[14]}$.

Este artículo concluía que "Históricamente, por el hecho de que cuando la fotografía del Carrión mestizo fue publicada, 
en las primeras décadas del siglo $X X$, no hubo ningún cuestionamiento al respecto por los que conocieron a Carrión ni por los historiadores de la medicina nacional; $y$, por el estudio de la igualdad de las proporciones faciales de las fotografías atribuidas a Carrión, se debe asumir que se trató de la misma persona; $y_{1}$ que tal vez las diferencias estén en relación con afeites por un lado, y por retoques, muy de moda en el sigloXIX y tan antiguo como la misma fotografía. Después de todo, la controversia suscitada ha servido para conocer mejor al mártir de la medicina peruana" ${ }^{[14]}$.

- En 2015 se publicó el libro Daniel Carrión García. Estudio histórico, iconográfico y antropológico forense de Ricardo Álvarez Carrasco, que en su capítulo XIV, incluyó la investigación de la doctora Caroline Wilkinson, afamada antropóloga forense británica, que sólo comparó la Fotografía familiar con la Fotografía individual, concluyendo lo siguiente ${ }^{[4,17]}$ :

"Hay similitudes morfológicas y proporcionales entre las caras del Hombre A y el Hombre B. No existen diferencias morfológicas o proporcionales aparentes entre ambos hombres que no se puedan explicar por las diferencias en el ángulo de las imágenes, la expresión facial o las diferencias de edad".

"No hay diferencias faciales aparentes que excluyan la posibilidad que el Hombre A pueda ser la misma persona que el Hombre B. Sin embargo, estas imágenes no son lo suficientemente consistentes a la vista y el detalle para identificar positivamente a ambos hombres".

\section{CONCLUSIONES}

1. La Fotografía familiar, cuyo original no se dispone a la fecha, es una imagen auténtica de Carrión, su padrastro y sus dos medios hermanos.

2. La Fotografía individual, cuyo original no se dispone a la fecha, de acuerdo a las diversas pruebas históricas, iconográficas y antropológico- forenses que hemos expuesto, también sería un retrato genuino de Carrión.

3. La Fotografía militar plantea todo un reto para los investigadores, no sólo por su reciente difusión, sino fundamentalmente porque hasta la fecha no se ha documentado suficientemente la plaza que ocupó Carrión durante la defensa de Lima (1881).

Respecto a su autenticidad, el único elemento de juicio que tenemos hasta el día de hoy es la investigación efectuada por Pamo y sus colaboradores (2014), que habría que reafirmar mediante otro estudio antropológico forense.

4. La búsqueda e identificación cierta de los restos óseos de Daniel Carrión García, es necesaria, tanto en el Mausoleo del Cementerio Presbítero Maestro como en la Cripta Mausoleo del Hospital Nacional Dos de Mayo de Lima, con el propósito de:

- Corroborar indubitablemente su existencia.

- Establecer científicamente su autenticidad, mediante el estudio comparativo del ADN de los huesos hallados en tales tumbas, con los de su hermano Teodoro Crisanto
Valdivieso García, que se halla sepultado en el nicho D-106 del Departamento Central San Job del Cementerio Presbítero Maestro.

- Reconstruir el rostro de Carrión, una vez autentificado su cráneo, mediante las técnicas forenses modernas que ya existen en nuestro país, y así poder compararlo antropométricamente con las tres fotografías que se le atribuyen

\section{EPÍLOGO}

Los médicos somos hombres de ciencia y debemos utilizar toda la tecnología disponible para alcanzar la verdad histórica, en particular para resolver un asunto tan delicado como la genuina fisonomía de nuestro héroe y mártir, don Daniel Carrión García. Es una manera objetiva de garantizar que las conclusiones finales de esta investigación sean incontrovertibles y resistan cualquier análisis posterior.

\section{REFERENCIAS BIBLIOGRÁFICAS}

1. Schwarz H. Los fotógrafos franceses en el Perú del siglo XIX. Rev Bulletin de l'Institut Français d'Études Andines. 2007;36(1):39-49.

2. Herrera A. La Lima de Eugenio Courret 1863-1934. 2da edición. Lima: Talleres Gráficos Novecientos Seis S.A.; 2001.

3. MajlufN, Wuffarden L. La recuperación de la memoria. Perú 18421942. Madrid: Gráficas Deva; 2001.

4. Álvarez R. Daniel Carrión García. Estudio histórico, icnográfico y antropológico forense. Primera edición. Lima: MagrafEIRL; 2015

5. Álvarez R. Aportes a la iconografía de Daniel Carrión García. An Fac Med. 2012;73(4):345-50.

6. Álvarez R. La historia del Instituto Nacional Materno Perinatal a través de las imágenes. 1ra edición. Lima: Industria gráfica Cimagraf SAC; 2014 .

7. Malpartida B. La verdadera gloria de Daniel A. Carrión. 1ra edición. Lima: Reprox S.A.; 2013.

8. Daniel A. Carrión. La Crónica Médica. 1885;2(22):396-401.

9. García U. Historia crítica de Daniel A. Carrión y de la Medicina de su época [Tesis Doctoral]. Lima, Perú: Universidad Peruana Cayetano Heredia; 1972.

10. Nuestros grabados. El Perú llustrado. 1887;1(27):1-3.

11. Valdizan H. Apuntes para una bibliografía peruana de la enfermedad de Carrión. An Fac med. 1925;11:45-85.

12. Conmemoración del Aniversario de Carrión - El Museo Daniel A. Carrión. An Fac med. 1954;37(4):774-814.

13. Pérez C. La Columna Pasco. Lima: Ediciones El Pueblo; 2013.

14. Pamo O, Humpire D, Fucay L. Sobre el rostro de Carrión. Rev Soc Peru Med Interna. 2014;27(1):27-32.

15. Herrera J. La Universidad Mayor de San Marcos y la Guerra del Pacífico. 2 da edición. Lima: Talleres gráficos de la editorial Universo; 1981.

16. La Gesta de Lima. Comisión permanente de historia del Ejército Peruano. 1ra edición. Lima: Imprenta del Ministerio de Guerra; 1981.

17. Wilkinson C. Facial imagen comparison report. Dundee: Center for Anatomy \& Human Idenfication, University of Dundee; 2014. 